\title{
Intestinal Microcirculatory Dysfunction During the Development of Experimental Necrotizing Enterocolitis
}

\author{
YOSHIYA ITO, SARAH M. DOELLE, JESSICA A. CLARK, MELISSA D. HALPERN, ROBERT S. MCCUSKEY, \\ AND BOHUSLAV DVORAK
}

\author{
Departments of Cell Biology [Y.I., R.S.M., B.D.] and Anatomy and Pediatrics [S.M.D., J.A.C., M.D.H., B.D.], \\ University of Arizona, Tucson, AZ 85724
}

\begin{abstract}
The aim of this study was to evaluate changes in intestinal microcirculation during necrotizing enterocolitis (NEC) and to examine the effect of endothelin (ET)-1 on the intestinal microcirculation. Prematurely born rats were either hand-fed formula (NEC) or dam fed (DF) and were exposed to asphyxia and cold stress twice daily to induce disease. At 0,2,3, and $4 \mathrm{~d}$ after the birth, the microcirculation in the ileum was examined using in vivo microscopic methods. The nutritive microvascular perfusion in the NEC group was progressively compromised from d 3 to $\mathrm{d} 4$ (35\% and 50\% decrease, respectively) when compared with DF rats. Concomitantly, intestinal blood flow assessed by laser Doppler flowmetry was significantly reduced at $\mathrm{d} 2,3$, and 4 (by $31 \%, 36 \%$, and $73 \%$, respectively). Levels of ET-1 mRNA in the ileum were increased 3.7-fold. Microvascular responses to topically applied ET-1 were significantly increased in the NEC group, which was associated with decreased expression of $\mathrm{ET}_{\mathrm{B}}$ receptor. These results suggest that microcirculatory dysfunction in the distal ileum of neonatal rats with NEC contributes to disease progression and that enhanced microvascular responsiveness to ET-1 may participate in these microcirculatory disturbances. (Pediatr Res 61: 180-184, 2007)
\end{abstract}

$\mathrm{N}^{\mathrm{E}}$ $\mathrm{EC}$ is the most common gastrointestinal emergency of premature infants (1). The incidence of NEC has been increasing, and the disease is associated with significant morbidity and mortality (2). The pathogenesis of NEC remains uncertain;, however, intestinal hypoxia/ischemia in the perinatal period appears to be one of the contributing factors to development of this disease (1,3). Indeed, high incidence of intestinal injury has been shown in severely asphyxiated neonates $(4,5)$. Severe hypoxia or long duration of intestinal ischemia followed by reperfusion causes a significant reduction in intestinal blood flow in newborn animals, which is associated with the histopathological findings seen in NEC (6-9). These findings suggest that perinatal insults that impair intestinal blood flow induce intestinal mucosal injury in neonates. While alterations in intestinal hemodynamics could compromise intestinal microcirculation in neonates, there have been few observations of sequential alterations in intestinal microcirculation during the development of NEC.

Received May 11, 2006; accepted September 13, 2006

Correspondence: Bohuslav Dvorak, Ph.D., Department of Pediatrics, University of Arizona, 1501 N. Campbell Avenue, PO Box 245073, Tucson, AZ 85724-5073; e-mail: dvorakb@peds.arizona.edu

This work was supported by the National Institute of Child Health and Human Development grant HD39657 (to B. Dvorak).

DOI: $10.1203 / p d r .0 b 013 e 31802 d 77 d b$
Endothelin is a potent and long-lasting vasoconstrictor that plays a putative role in regulating microcirculation in the intestine (3). The administration of ET-1 increases the vascular resistance of the intestine and decreases intestinal blood flow in neonatal piglets (10). In vivo microscopic studies have demonstrated that ET-1 narrows the lumen of microvessels in the submucosa of the small intestine in adult rodents (11). Selective $\mathrm{ET}_{\mathrm{A}}$ receptor antagonist inhibits constriction of isolated subserosal arterioles from human infants with NEC (12). In addition, increased ET-1 levels are shown in the intestines from human infants with NEC (12). These results suggest that ET-1 participates in the intestinal microcirculatory dysfunction during the development of NEC.

The aim of the present study was to evaluate the sequential changes in microcirculation in the ileum during the development of NEC. To achieve this aim, we induced NEC in neonatal rats using formula feeding coupled with exposure to asphyxia/cold stress. We examined the development of microcirculatory alterations in the distal ileum of neonatal rats using in vivo microscopic methods. We also examined the effect of ET-1 on the intestinal microcirculation in NEC rats.

\section{MATERIALS AND METHODS}

Experimental animals. The present study was performed in adherence to the National Institutes of Health guideline for the use of experimental animals. The protocol was approved by the Animal Care and Use Committee of the University of Arizona (A-324801-95081). Neonatal Sprague-Dawley rats (Charles River Laboratories, Pontage, MI) were collected by cesarean section $1 \mathrm{~d}$ before scheduled birth. Pups were either hand-fed with cow's milk-based rat milk substitute formula (NEC) using nonsterile feeding catheters or DF. To induce experimental NEC, rat pups from both experimental groups were stressed twice daily with asphyxia (breathing 100\% nitrogen gas for $60 \mathrm{~s}$ ) followed by cold $\left(4^{\circ} \mathrm{C}\right.$ for $\left.10 \mathrm{~min}\right)(13-17)$. All experimental measurements were performed at least $12 \mathrm{~h}$ after the last asphyxia/cold stress exposure.

In vivo microscopy. At $0,2,3$, and $4 \mathrm{~d}$, animals were anesthetized with an s.c. injection of a mixture of ketamine $(100 \mathrm{mg} / \mathrm{kg})$ and xylazine $(10 \mathrm{mg} / \mathrm{kg})$. The intestinal microvascular responses were examined using established high resolution in vivo microscopic methods $(18,19)$. Briefly, a compound binocular microscope (Leitz, Wetzlar, Germany) adapted for in vivo microscopy was equipped to provide either transillumination or epi-illumination as well as video microscopy using a charge-coupled device camera (MTI, Michigan City, IN). The ileum was exteriorized through a lower abdominal incision and positioned over a window of optical grade mica in a specially designed tray mounted on a microscopic stage. The tray provided for the drainage of irrigating fluids, and the window overlaid a long working distance condenser. The terminal ileum of the intestine was covered by a piece of Saran Wrap

Abbreviations: CVs, collecting venules; DF, dam fed; ET, endothelin; FMD, functional microvascular density; NEC, necrotizing enterocolitis 
(Dow Chemical, Midland, MI), which held it in position and limited movement. Homeostasis was ensured by a constant suffusion of the organ with Ringer's solution maintained at body temperature.

The microvessels within the submucosa were observed from the serosal side and were visualized by changing the focus of the microscope. The microscopic images were obtained with a long working distance objective lens (32x NA 0.6, Leitz, Wetzlar, Germany). Microvascular events were observed and recorded for subsequent offline analysis using a Sony Betacam video tape recorder (Sony Medical Electronics, Park Ridge, NJ).

Analysis of in vivo microscopy. Microvessels in the outer surface of the submucosal layer were classified according to their order of branching. As described by Gore and Bohlen (20), the intestinal microcirculation commences as the first-order arterioles $(1 \mathrm{~A})$ that subsequently give rise to the second-order arteriole (2A) branches, and then finally to the third-order arteriole (3A) branches, each of which becomes a villous arteriole. Capillaries arise from the $3 \mathrm{~A}$ only, both within the crypt region and the villus. Villous venules combine to form collecting venules (CVs) in the deep mucosa, which coalesce to form the second-order venules $(2 \mathrm{~V})$ and thereafter the first-order venules $(1 \mathrm{~V})$. To evaluate the perfusion through the submucosa, the total length of perfused submucosal terminal arterioles (3A), capillaries, and submucosal CVs per observation area was measured (21), and expressed as functional microvascular density (FMD) $\left(\mu \mathrm{m} / 10,000 \mu \mathrm{m}^{2}\right)$. The FMD was determined in three different areas.

The relative velocity of blood flow in arterioles (1A) and venules (1V) in the submucosa was estimated by using a scale of $4+$ to 0 where $4+=$ rapid flow, no cellular detail visible; $3+=$ moderate flow, blurred images of cells visible; $2+=$ slow flow, cellular elements distinctly visible; $1+=$ pulsatile flow but in a progressively forward direction, and $0=$ stasis or no flow (22).

To examine the interaction of leukocytes with endothelium in the venules, the number of leukocytes adhering was determined offline during video playback analysis. A leukocyte was defined as adhering to the venular walls if it remained stationary for more than $30 \mathrm{~s}$. The endothelial surface area of the venule was measured from video recordings using a computer-assisted digital imaging processor (Scion Image, Scion Corp., Frederick, MD). The number of adhering leukocytes was counted, and the data were expressed as the average number of adhering leukocytes per $10,000 \mu \mathrm{m}^{2}$ of endothelial surface area of the venules.

To examine the response of microvessels to ET-1, arterioles and venules were selected, and their internal diameters were measured using a computerassisted digital imaging processor (Scion Image). The results were expressed as the percentage of constriction or percentage of dilatation. The percentage of constriction and dilatation were calculated as follows: \% change of diameter $=100 \times[$ (prediameter $)-($ postdiameter $)] /($ prediameter $)$.

Laser Doppler flowmetry. The blood flow in the ileum was measured by laser Doppler flowmetry using a laser Doppler flowmeter (Moor Instruments, Wilmington, DE). A microprobe (P5a/P5b) was placed on the surface of the ileum. Three different sites of the ileum were examined to measure the blood flow. The laser Doppler flowmetry signal was digitized with Moor Lab software (Moor Instruments). The results were averaged and expressed as arbitrary units.

ET-1 application. In a separate set of experiments, a plastic ring (external diameter, $6 \mathrm{~mm}$; internal diameter, $5 \mathrm{~mm}$; thickness, $0.3 \mathrm{~mm}$ ) was placed on the surface of the ileum to form an observation window. The suffusion with warmed Ringer's solution was stopped $30 \mathrm{~s}$ before application of the drugs. ET-1 $(0.1$ and $1 \mu \mathrm{mol} / \mathrm{L}, 50 \mu \mathrm{L})$ (Phoenix Pharmaceuticals, Inc., Phoenix, AZ) or vehicle (saline) was topically applied to the window in 3-d-old NEC and DF animals. Observations were made for 10 min following the administration of ET-1.

RNA preparation. In a separate set of experimental animals, total RNA was isolated form ileal tissue using the RNeasy Mini Kit (Qiagen, Santa Clarita, CA) as described before (14-16). All samples were incubated with RNase-free DNase (20 U/reaction) for $10 \mathrm{~min}$ at $37^{\circ} \mathrm{C}$ to eliminate DNA contamination. RNA concentration was quantified by UV spectrophotometry at $260 \mathrm{~nm}$, and the purity was determined by the ratio of absorbance at $260 \mathrm{~nm}$ to that at $280 \mathrm{~nm}$ (SPECTRmax PLUS; Molecular Devices, Sunnyvale, CA). The integrity of RNA was verified by electrophoresis on a $1.2 \%$ agarose gel containing formaldehyde $(2.2 \mathrm{~mol} / \mathrm{L})$ and ethidium bromide in $1 \times 3-(N-$ morpholino)propanesulfonic acid (MOPS) buffer $[40 \mathrm{mmol} / \mathrm{L}$ MOPS $(\mathrm{pH}$ 7.0), $10 \mathrm{mmol} / \mathrm{L}$ sodium acetate, and $1 \mathrm{mmol} / \mathrm{L}$ ethylenediamine tetraacetic acid (EDTA) (pH 8.0)].

Reverse-transcriptase (RT) and real-time PCR. RT real-time PCR assays were performed to specifically quantify rat ET-1 steady state mRNA levels. cDNA was synthesized from $0.5 \mu \mathrm{g}$ of DNase-treated total RNA. Predeveloped TaqMan primer and probe were used for detection of ET-1 (Applied Biosystems, Foster, CA). Target probes were labeled with fluorescent reporter dye FAM (23). Reporter dye emission is detected by an automated sequence detector combined with ABI Prism 7700 Sequence Detection System software
(Applied Biosystems). Real-time PCR quantification was then performed using TaqMann $18 \mathrm{~S}$ controls. Relative quantification of PCR products were then based on value differences between the target and $18 \mathrm{~S}$ control using the comparative $\mathrm{C}_{\mathrm{T}}$ method (24). Cycle parameters were $55^{\circ} \mathrm{C} \times 5 \mathrm{~min}, 95^{\circ} \mathrm{C} \times$ $10 \mathrm{~min}$, and then 40 cycles of $95^{\circ} \mathrm{C} \times 15 \mathrm{~s} 58^{\circ} \mathrm{C} \times 60 \mathrm{~s}$. For every sample, each PCR reaction was performed on three separate occasions; in each set of reactions, every sample was present in triplicate.

Western blot. Individual frozen ileum samples were homogenized with a handheld homogenizer (Pellet Pestle, Kimble/Kontes, Vineland, NJ) in a $5 \times$ volume of ice-cold homogenization buffer $(50 \mathrm{mmol} / \mathrm{L}$ Tris $\mathrm{HCl}, \mathrm{pH} 7.4 ; 150$ $\mathrm{mmol} / \mathrm{L} \mathrm{NaCl} ; 1 \mathrm{mmol} / \mathrm{L}$ EDTA; $0.1 \%$ SDS; $1 \%$ Na-deoxycholic acid; $1 \%$ Triton X-100; $50 \mathrm{mmol} / \mathrm{L}$ DTT; $50 \mu \mathrm{g} / \mathrm{mL}$ aprotinin; $50 \mu \mathrm{g} / \mathrm{mL}$ leupeptin; 5 $\mathrm{mmol} / \mathrm{L}$ PMSF). The homogenates were centrifuged at 10,000 rpm for $5 \mathrm{~min}$ at $4^{\circ} \mathrm{C}$ and the supernatant was collected. Total protein concentration was quantified using the Bradford protein assay (25). For protein analysis, $40 \mathrm{~g}$ of protein was added to an equal volume of $2 \times$ Laemmli sample buffer and boiled for $5 \mathrm{~min}$. The samples were run on a $10 \%-20 \%$ gradient polyacrylamide gel (Bio-Rad, Hercules, CA) at $95 \mathrm{~V}$ for $1 \mathrm{~h}$. Protein was transferred to Immuno-Blot PVDF membranes (Bio-Rad) at $30 \mathrm{~V}$ for $1 \mathrm{~h}$. Membranes were blocked with $5 \%$ nonfat milk in Tris-buffered saline with $0.1 \%$ Tween 20 (Sigma Chemical Co., St. Louis, MO) for $1 \mathrm{~h}$ at room temperature and then incubated with a goat polyclonal anti-ET $\mathrm{A}_{\mathrm{A}}$ receptor antibody or a goat polyclonal anti-ET ${ }_{B}$ receptor antibody (Santa Cruz Biotechnology, Santa Cruz, CA) overnight at $4^{\circ} \mathrm{C}$. After being washed, the membranes were incubated for $1 \mathrm{~h}$ at room temperature with horseradish peroxidaseconjugated donkey anti-goat IgG (Santa Cruz Biotechnology). Proteins were visualized with a chemiluminescent system (Pierce, Rockford, IL) and exposed to X-ray film. Densitometry was performed to compare protein expression between groups with Bio-Rad QuantityOne software.

Statistical analysis. All data were expressed as means \pm standard error of the mean. Multiple comparisons were performed using one-way analysis of variance (ANOVA) with a post hoc Fisher test. Differences were considered to be significant for $p$ values $<0.05$.

\section{RESULTS}

Sequential changes in intestinal microcirculation in neonates with NEC. Sequential changes in microcirculation in the ileum during the development of NEC are shown in Fig. 1. In vivo microscopic studies showed that the functional microvascular density (FMD) in 3A, capillaries, and CVs in the NEC group was significantly and progressively reduced at $\mathrm{d} 3$ (34.7\% decrease) and d 4 (50.3\% decrease) when compared with DF rats (Fig. 1A). In contrast, DF rats exhibited no
A

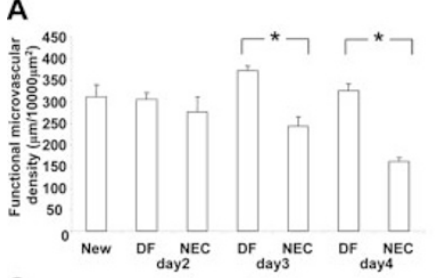

C

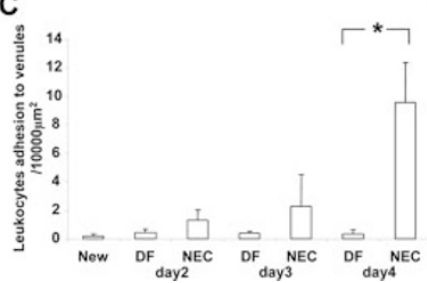

B
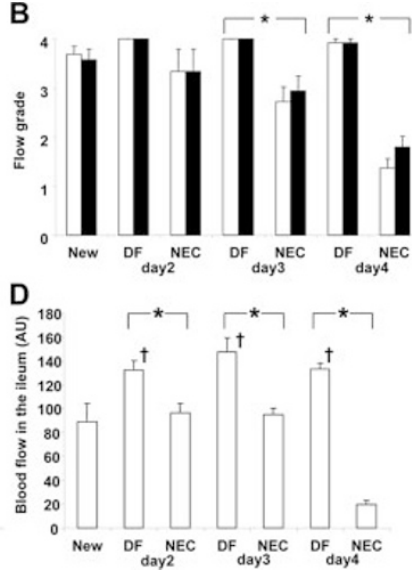

Figure 1. Changes in functional microvascular density (A), flow grade in arterioles (open columns) and venules (solid columns) (B), and adherent leukocytes $(C)$ assessed by in vivo microscopy and blood flow $(D)$ assessed by Laser Doppler flowmetry during the evolution of experimental NEC. The FMD was expressed as the ratio of total length of perfused $3 \mathrm{~A}$, capillaries, and $\mathrm{CV}$ s to the observation area. The grade of blood flow velocity was determined in $1 \mathrm{~A}$ and $1 \mathrm{~V}$ vessels. Data are mean \pm standard error from four to six animals per group. ${ }^{*} p<0.05, \dagger p<0.05$ vs newborn rats (New). 

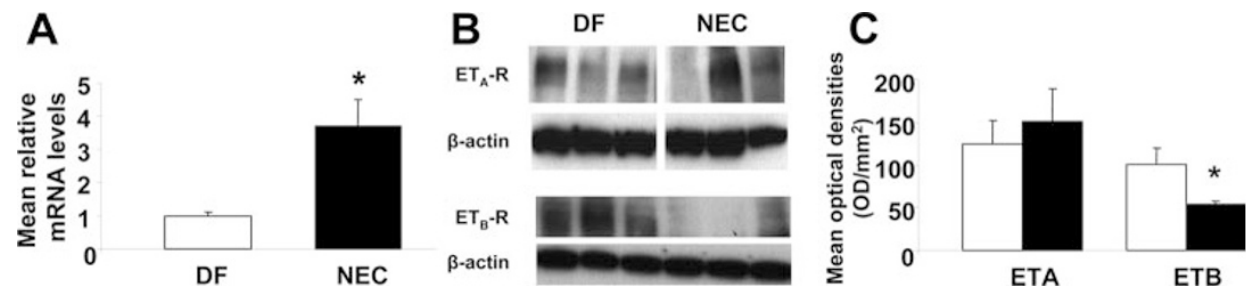

Figure 2. ET-1 mRNA levels and expression of $\mathrm{ET}_{\mathrm{A}}$ and $\mathrm{ET}_{\mathrm{B}}$ receptor in NEC animals at d 4. (A) ET-1 mRNA in the ileum of DF (open columns) and NEC (solid columns) animals was measured by real-time PCR. The mean steady-state mRNA level for the DF group was assigned a value of 1.0 and the mean mRNA from the NEC group was determined relative to this number. $(B)$ Representative Western blots for $\mathrm{ET}_{\mathrm{A}}$ and $\mathrm{ET}_{\mathrm{B}}$ receptors in the ileum. $(C)$ Mean optical densities for active $\mathrm{ET}_{\mathrm{A}}$ receptor and $\mathrm{ET}_{\mathrm{B}}$ receptor taken from Western blots. Data are mean \pm standard error from 12 animals in each group. ${ }^{*} p<0.05 v s$ DF animals.

significant changes in FMD in 3A, capillaries, and CVs throughout the experiment. Concomitantly, the blood flow velocity in large arterioles $(1 \mathrm{~A})$ and venules $(1 \mathrm{~V})$ was compromised in NEC rats, while DF rats exhibited rapid flow in $1 \mathrm{~A}$ and $1 \mathrm{~V}$ (Fig. 1B). During the first $3 \mathrm{~d}$ of the study, there were no significant increases in the number of leukocytes adhering to the venules between DF and NEC groups. However, at $\mathrm{d} 4$, the number of adherent leukocytes in the NEC group was increased (22-fold) when compared with DF rats (Fig. 1C). The ileal blood flow assessed by laser Doppler flowmetry in the NEC group at $\mathrm{d} 2,3$, and 4 was significantly reduced by $31 \%, 36 \%$, and $73 \%$, respectively (Fig. $1 \mathrm{D}$ ). In addition, the levels of ileal blood flow in DF rats were increased when compared with newborn rats.

Expression of ET-1 levels and ET receptor in the ileum. Ileal expression of ET-1 mRNA at d 4 was significantly increased in the NEC group (three- to fourfold) in comparison with that in the age-matched DF group (Fig. 2A). The expression of $\mathrm{ET}_{\mathrm{A}}$ receptor in NEC rats was similar to that in $\mathrm{DF}$ rats, while the expression of $\mathrm{ET}_{\mathrm{B}}$ receptor in NEC rats was significantly decreased by $47 \%$ (Fig. $2 B$ ).

Intestinal microvascular response to ET-1. To investigate whether ET-1 elicits microcirculatory dysfunction in the ileum, we topically applied ET-1 over the surface of the ileum of neonatal rats at $d$ 3. As shown in Figure 3, application of 1 $\mu \mathrm{mol} / \mathrm{L}$ ET-1 elicited marked constriction of arterioles (1A) in

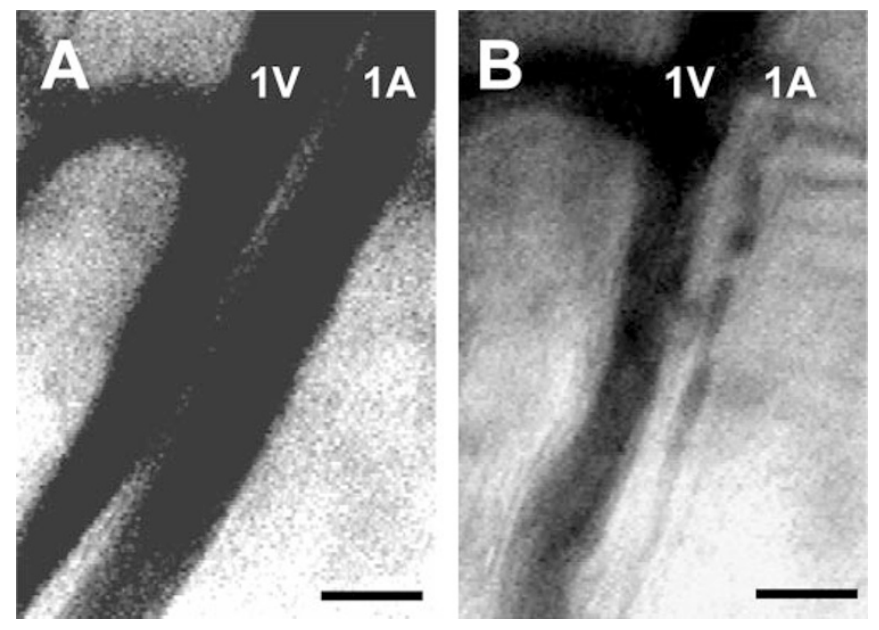

Figure 3. In vivo micrographs showing microvascular changes before $(A)$ and 10 min after $(B)$ the application of ET-1 in NEC animals. ET-1 (1 $\mu \mathrm{mol} / \mathrm{L}$ ) caused marked constriction of arterioles (1A) and slightly reduced the diameters of venules (1V) in NEC animals at d 3. Bars indicate $30 \mu \mathrm{m}$. the NEC group. Figure 4 illustrates changes in the diameters of arterioles and venules 10 min after ET-1 application. In DF rats, $0.1 \mu \mathrm{mol} / \mathrm{L}$ ET-1 did not change the diameters of arterioles and venules; however, $1 \mu \mathrm{mol} / \mathrm{L}$ ET-1 caused marked constriction. The major sites of the constriction in response to ET-1 were located in 1A arterioles and the vasoconstriction lasted for at least $10 \mathrm{~min}$ (not shown). In contrast, ET-1 (0.1 $\mu \mathrm{mol} / \mathrm{L}$ ) significantly reduced the diameters of $1 \mathrm{~A}$ and $2 \mathrm{~A}$ arterioles in the NEC group, indicating that the microvascular response to ET-1 was enhanced. When the intestinal microvasculature of NEC rats was exposed to $1 \mu \mathrm{mol} / \mathrm{L}$ ET-1, the diameter of arterioles (1A) was also significantly reduced. The microvascular responses to ET-1 $(1 \mu \mathrm{mol} / \mathrm{L})$ in the NEC group were similar to those in DF rats; however, the constrictor responses of arterioles (2A and $3 \mathrm{~A}$ ) in the NEC group were greater than those in DF rats.

Figure 5 shows the effect of ET- 1 on FMD in NEC and DF rats. The effect was expressed by changes in the functional microvascular density before and after ET-1 application. ET-1 $(0.1 \mu \mathrm{mol} / \mathrm{L})$ did not significantly change the microvascular

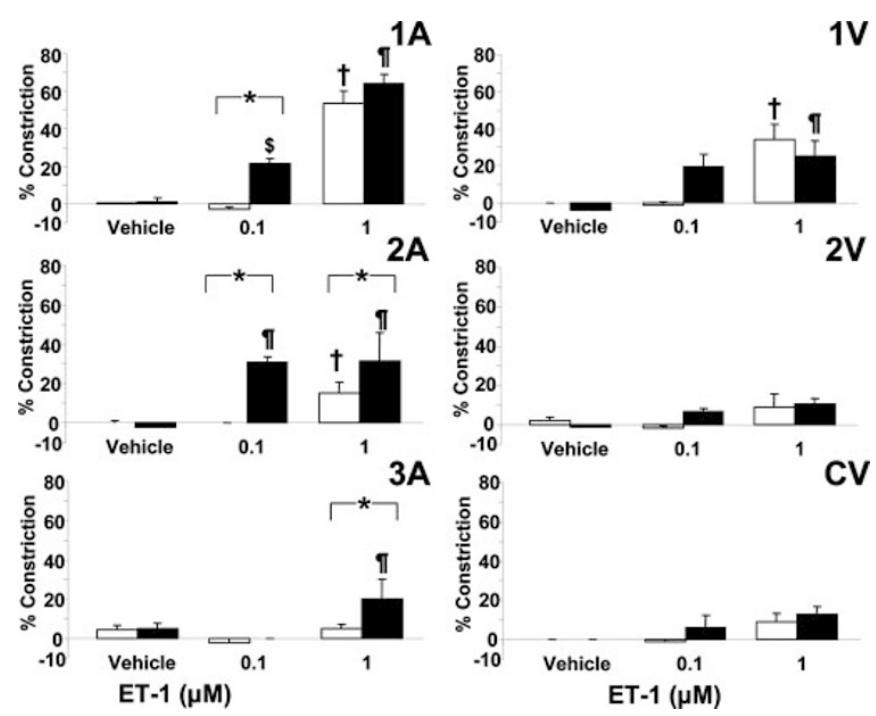

Figure 4. Effect of ET-1 on the diameters of arterioles (left) and venules (right) in the ileum from DF (open columns) and NEC (solid columns) rats $3 \mathrm{~d}$ after the birth. ET-1 ( 0.1 or $1 \mu \mathrm{mol} / \mathrm{L})$ or vehicle (saline) was applied over the surface of the ileum. The diameters of the arterioles (1A, 2A, and 3A) and venules $(1 \mathrm{~V}, 2 \mathrm{~V}$, and CV) were measured $10 \mathrm{~min}$ after ET-1 application. Data are mean \pm standard error from three to six animals per group. ${ }^{*} p<0.05$, $\dagger p<0.05 v s$ DF rats treated with vehicle; $p<0.05 v s$ NEC rats treated with vehicle. 


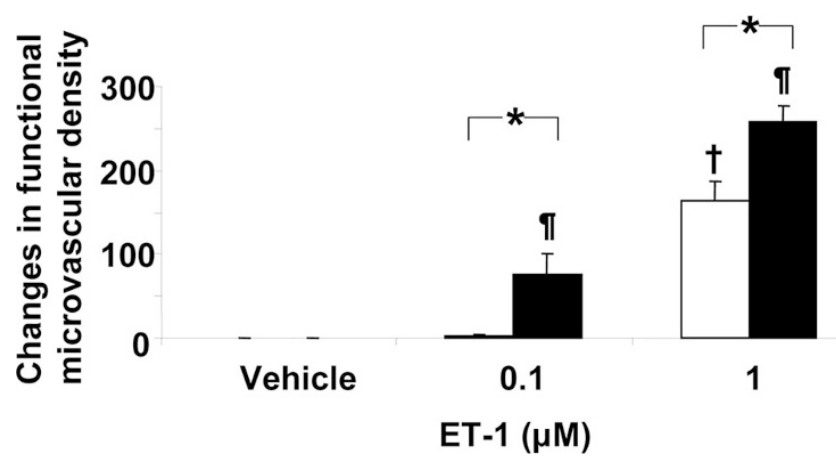

Figure 5. Effect of ET-1 on FMD. The microvascular perfusion in the NEC group was significantly impaired by ET-1 application. The changes in microvascular perfusion were measured $10 \mathrm{~min}$ after ET-1. Data are mean \pm standard error from three to six animals per group. ${ }^{*} p<0.05 ; \dagger p<0.05 v s$ DF (open columns) rats treated with vehicle; $p<0.05$ vs NEC (solid columns) rats treated with vehicle.

perfusion in DF rats, while the same concentration of ET-1 caused a significant decrease in NEC rats. Moreover, 1 $\mu \mathrm{mol} / \mathrm{L}$ ET-1 significantly reduced the microvascular perfusion in both DF and NEC rats, although the magnitude was greater in NEC rats than DF rats (Fig. 5).

\section{DISCUSSION}

Changes in intestinal microcirculation in NEC animals. Hypoxia or intestinal ischemia followed by reperfusion has been shown to cause a significant decrease in intestinal blood flow in neonatal piglets $(3,6,9)$. However, severe hypoxia or longer duration of ischemic time is necessary to generate tissue damage. Using our established NEC model $(14,16,17)$, we determined that intestinal blood flow, assessed by laser Doppler flowmetry, is reduced in the NEC group as early as $2 \mathrm{~d}$ after initiating stress. In contrast, no significant change in blood flow was seen in stressed DF rats throughout the experiment period, suggesting that hypoxia and hypothermia by themselves are unable to create sustained impairment of blood flow in the neonatal ileum. In addition to repetitive stress, artificial feeding is required to elicit not only NEC pathology $(15,26)$ but also impaired intestinal blood flow. Reduced intestinal blood flow during the development of NEC indicates impairment in microvascular perfusion in NEC rats. As a result, we observed the intestinal microcirculation in neonatal rats directly using in vivo microscopic methods. In the NEC group, the grade of blood flow in large submucosal arterioles (1A) and venules (1V) decreased from $3 \mathrm{~d}$ after initiating asphyxia and cold stress. Concomitantly, the microvascular perfusion was impaired. Prolonged microcirculatory disturbance in the ileum could compromise delivery of oxygen supply to the tissue. In addition, the number of leukocytes adhering to the venules in the NEC group was significantly increased. Activated adherent leukocytes as well as endothelial cells would produce reactive oxygen species and promote the formation of inflammatory mediators (26), contributing to intestinal injury during NEC. These results indicate that intestinal microcirculatory dysfunction in neonatal rats is related to the development of NEC.
It is not technically feasible to monitor the systemic blood pressure, respiratory rate, tissue temperature, and hemoglobin saturation during in vivo microscopic studies in the small neonatal rat pups. However, since NEC rats at d 4 were sicker than DF rats (14), NEC rats appeared to be susceptible to the physiologic perturbations during the experimental preparation. Thus, it is plausible that NEC rats might have experienced more cardiovascular compromise, which affects the ileal microcirculation in the NEC group.

Increased expression of ET-1 in NEC. To understand the mechanisms of intestinal microcirculatory dysfunction in NEC, we determined ET-1 levels in the ileum. The results show that ET-1 mRNA expression in the ileum from NEC rats is significantly increased. In agreement with this result, Nowicki et al. (12) have recently shown that ET-1 is elevated in human intestinal tissue affected with NEC, suggesting that ET-1 contributes to the development of this disease. The production sites of ET-1 in the intestine have been reported to be within the vascular endothelial cells, submucosal stroma, and circular muscle layer (27). Because ET-1 levels are not up-regulated in DF rats, ET-1 could be stimulated by a combination of hypoxia/hypothermia, inflammatory cytokines (28-30), and reduced blood flow rate (31). Also, glucocorticoids have been shown to up-regulate preproendothelin transcriptionally (32). Recently, we have reported increased levels of plasma corticosterone in the neonatal rat model of NEC (14). Thus, increased ET-1 levels may be attributed to increased glucocorticoid production during the development of NEC. Since ET-1 is a strong and long-lasting vasoconstrictor, these results suggest that ET-1 is involved in microcirculatory dysfunction in NEC animals.

Enhancement of ET-1 responsiveness in microcirculatory dysfunction. Previous studies have reported that exogenous ET-1 raises intestinal vascular resistance in neonatal piglets (10). The current study shows that the application of ET-1 to the ileum predominantly constricts arterioles (1A) in DF rats, but does not change the diameter of the terminal microvessels. Consistent with this result, King-VanVlack et al. (11) have shown that ET-1 superfusion causes vasoconstriction in proximal arterioles ( $1 \mathrm{~A}$ and $2 \mathrm{~A}$ ) of adult rodents, but not in terminal arterioles, and the vasoconstriction is mediated through the $\mathrm{ET}_{\mathrm{A}}$ receptor subtype. Potent constriction of larger arterioles results in impaired downstream microvascular perfusion, leading to local hypoxia and intestinal injury. Further studies are necessary to examine the mechanisms by which ET-1 causes microvascular dysfunction in NEC animals. The concentrations of ET-1 that were effective on the microvessels of the neonates in the current study were higher than those in adult rats (33). This reduced sensitivity of microvessels to ET-1 may be due to differences in receptor sensitivity and/or density between neonatal and adult rats or compromised preparation.

Moreover, in our NEC model, the vasoconstrictor response to ET-1 in the NEC group is increased. To determine whether the increased vasoconstrictor response to ET-1 is attributable to $\mathrm{ET}$ receptor up-regulation, $\mathrm{ET}_{\mathrm{A}}$ and $\mathrm{ET}_{\mathrm{B}}$ receptor protein expression in the distal ileum was evaluated. Although $\mathrm{ET}_{\mathrm{A}}$ receptor expression is unchanged between NEC and DF 
groups, $\mathrm{ET}_{\mathrm{B}}$ receptor expression is significantly suppressed in NEC pups. Since $\mathrm{ET}_{\mathrm{B}}$ receptor on smooth muscle cells mediates vasodilation through the release of prostacyclin and nitric oxide, decreased expression of $\mathrm{ET}_{\mathrm{B}}$ receptor would create an imbalance between constrictor and dilator stimuli, favoring constriction. Thus, these results suggest that enhanced response of microvessels to ET-1 in the NEC group appears to be mediated through down-regulation of $\mathrm{ET}_{\mathrm{B}}$ receptor expression. However, $\mathrm{ET}_{\mathrm{B}}$ receptors also are abundant in the intestinal circular and longitudinal smooth muscle cells (34). Thus, it remains unknown whether $\mathrm{ET}_{\mathrm{B}}$ receptors on the endothelial cells were down-regulated in the present study. Furthermore, there are two subtypes of $\mathrm{ET}_{\mathrm{B}}$ receptor; $\mathrm{ET}_{\mathrm{B} 1}$ receptor subtype on the endothelial cells mediates vasodilation and $\mathrm{ET}_{\mathrm{B} 2}$ receptor subtype on the vascular smooth muscle cells mediates vasoconstriction. It remains unclear which $\mathrm{ET}_{\mathrm{B}}$ receptor subtype is attenuated.

In summary, the microcirculation in the ileum was progressively impaired with the development of experimental NEC. Increased expression of ET-1 mRNA in the ileum was associated with the microcirculatory dysfunction. The microvascular responses to ET-1 were enhanced in NEC rats which was associated with decreased expression of $\mathrm{ET}_{\mathrm{B}}$ receptors. These results suggest that intestinal microcirculatory dysfunction, including enhanced vasoconstrictor response to ET-1, contributes to the development of NEC.

\section{REFERENCES}

1. Neu J 1996 Necrotizing enterocolitis: the search for a unifying pathogenic theory leading to prevention. Pediatr Clin North Am 43:409-432

2. Lee JS, Polin RA 2003 Treatment and prevention of necrotizing enterocolitis. Semin Neonatol 8:449-459

3. Nowicki PT 2005 Ischemia and necrotizing enterocolitis: where, when, and how. Semin Pediatr Surg 14:152-158

4. Barnett CP, Perlman M, Ekert PG 1997 Clinicopathological correlations in postasphyxial organ damage: a donor organ perspective. Pediatrics 99:797-799

5. Martin-Ancel A, Garcia-Alix A, Gaya F, Cabanas F, Burgueros M, Quero J 1995 Multiple organ involvement in perinatal asphyxia. J Pediatr 127:786-793

6. Alward CT, Hook JB, Helmrath TA, Mattson JC, Bailie MD 1978 Effects of asphyxia on cardiac output and organ blood flow in the newborn piglet. Pediatr Res 12:824-827

7. Karna P, Senagore A, Chou CC 1986 Comparison of the effect of asphyxia, hypoxia, and acidosis on intestinal blood flow and $\mathrm{O} 2$ uptake in newborn piglets. Pediatr Res 20:929-932

8. Papparella A, DeLuca FG, Oyer CE, Pinar H, Stonestreet BS 1997 Ischemiareperfusion injury in the intestines of newborn pigs. Pediatr Res 42:180-188

9. Touloukian RJ, Posch JN, Spencer R 1972 The pathogenesis of ischemic gastroenterocolitis of the neonate: selective gut mucosal ischemia in asphyxiated neonatal piglets. J Pediatr Surg 7:194-205

10. Nankervis CA, Nowicki PT 2000 Role of endothelin-1 in regulation of the postnatal intestinal circulation. Am J Physiol Gastrointest Liver Physiol 278:G367-G375

11. King-VanVlack CE, Mewburn JD, Chapler CK, MacDonald PH 2003 Hemodynamic and proinflammatory actions of endothelin-1 in guinea pig small intestine submucosal microcirculation. Am J Physiol Gastrointest Liver Physiol 284:G940G948
2. Nowicki PT, Dunaway DJ, Nankervis CA, Giannnone PJ, Reber KM, Hammond SB, Besner GE, Caniano DA 2005 Endothelin-1 in human intestine resected for necrotizing enterocolitis. J Pediatr 146:805-810

13. Caplan MS, Hedlund E, Adler L, Hsueh W 1994 Role of asphyxia and feeding in a neonatal rat model of necrotizing enterocolitis. Pediatr Pathol 14:1017-1028

14. Clark JA, Lane RH, Maclennan NK, Holubec H, Dvorakova K, Halpern MD, Williams CS, Payne CM, Dvorak B 2005 Epidermal growth factor reduces intestinal apoptosis in an experimental model of necrotizing enterocolitis. Am J Physiol Gastrointest Liver Physiol 288:G755-G762

15. Dvorak B, Halpern MD, Holubec H, Williams CS, McWilliam DL, Dominguez JA, Stepankova R, Payne CM, McCuskey RS 2002 Epidermal growth factor reduces the development of necrotizing enterocolitis in a neonatal rat model. Am J Physiol Gastrointest Liver Physiol 282:G156-G164

16. Halpern MD, Clark JA, Saunders TA, Doelle SM, Hosseini DM, Stagner AM, Dvorak B 2006 Reduction of experimental necrotizing enterocolitis with anti-TNF- $\alpha$ Am J Physiol Gastrointest Liver Physiol 290:G757-G764

17. Halpern MD, Holubec H, Saunders TA, Dvorak K, Clark JA, Doelle SM, Ballatori N, Dvorak B 2006 Bile acids induce ileal damage during experimental necrotizing enterocolitis. Gastroenterology 130:359-372

18. McCuskey RS 1986 Microscopic methods for studying the microvasculature of internal organs.In: Baker CH, Nastuk WF (eds) Physical Techniques in Biology and Medicine Microvascular Technology. Academic Press, New York, pp 247-264.

19. McCuskey RS, Ekataksin W, LeBouton AV, Nishida J, McCuskey MK, McDonnell D, Williams C, Bethea NW, Dvorak B, Koldovsky O 2003 Hepatic microvascular development in relation to the morphogenesis of hepatocellular plates in neonatal rats. Anat Rec A Discov Mol Cell Evol Biol 275:1019-1030

20. Gore RW, Bohlen HG 1977 Microvascular pressures in rat intestinal muscle and mucosal villi. Am J Physiol 233:H685-H693

21. Gonzalez AP, Sepulveda S, Massberg S, Baumeister R, Menger MD 1994 In vivo fluorescence microscopy for the assessment of microvascular reperfusion injury in small bowel transplants in rats. Transplantation 58:403-408

22. McCuskey RS, Vonnahme FJ, Grun M 1983 In vivo and electron microscopic observations of the hepatic microvasculature in the rat following portacaval anastomosis. Hepatology 3:96-104

23. Pham TD, MacLennan NK, Chiu CT, Laksana GS, Hsu JL, Lane RH 2003 Uteroplacental insufficiency increases apoptosis and alters p53 gene methylation in the full-term IUGR rat kidney. Am J Physiol Regul Integr Comp Physiol 285:R962R970

24. Menon RK, Shaufl A, Yu JH, Stephan DA, Friday RP 2001 Identification and characterization of a novel transcript of the murine growth hormone receptor gene exhibiting development- and tissue-specific expression. Mol Cell Endocrinol 172:135-146

25. Bradford MM 1976 A rapid and sensitive method for the quantitation of microgram quantities of protein utilizing the principle of protein-dye binding. Anal Biochem $72: 248-254$

26. Barlow B, Santulli TV, Heird WC, Pitt J, Blanc WA, Schullinger JN 1974 An experimental study of acute neonatal enterocolitis-the importance of breast milk. J Pediatr Surg 9:587-595

27. Egidy G, Juillerat-Jeanneret L, Jeannin JF, Korth P, Bosman FT, Pinet F 2000 Modulation of human colon tumor-stromal interactions by the endothelin system. Am J Pathol 157:1863-1874

28. Halpern MD, Holubec H, Dominguez JA, Meza YG, Williams CS, Ruth MC, McCuskey RS, Dvorak B 2003 Hepatic inflammatory mediators contribute to intestinal damage in necrotizing enterocolitis. Am J Physiol Gastrointest Liver Physiol 284:G695-G702

29. Halpern MD, Holubec H, Dominguez JA, Williams CS, Meza YG, McWilliam DL, Payne CM, McCuskey RS, Besselsen DG, Dvorak B 2002 Up-regulation of IL-18 and IL-12 in the ileum of neonatal rats with necrotizing enterocolitis. Pediatr Res 51:733-739

30. Woods M, Mitchell JA, Wood EG, Barker S, Walcot NR, Rees GM, Warner TD 1999 Endothelin-1 is induced by cytokines in human vascular smooth muscle cells: evidence for intracellular endothelin-converting enzyme. Mol Pharmacol 55:902909

31. Kuchan MJ, Frangos JA 1993 Shear stress regulates endothelin-1 release via protein kinase C and cGMP in cultured endothelial cells. Am J Physiol 264:H150-H156

32. Thakali K, Fink GD, Watts SW 2004 Arteries and veins desensitize differently to endothelin. J Cardiovasc Pharmacol 43:387-393

33. Nowicki PT 1999 Effects of sustained low-flow perfusion on the response to vasoconstrictor agents in postnatal intestine. Am J Physiol 276:1408-1416

34. Nowicki PT 1998 Effects of sustained flow reduction on postnatal intestinal circulation. Am J Physiol 275:G758-G768 